\title{
Phylogeny of Thiobacillus cuprinus and Other Mixotrophic Thiobacilli: Proposal for Thiomonas gen. nov.
}

\author{
DAVID MOREIRA AND RICARDO AMILS* \\ Centro de Biología Molecular Severo Ochoa, Universidad Autónoma de Madrid, \\ Cantoblanco, 28049 Madrid, Spain
}

\begin{abstract}
The complete $5 \mathrm{~S}$ and $16 \mathrm{~S}$ ribosomal DNA (rDNA) sequences of the facultatively chemolithotrophic bacterium Thiobacillus cuprinus and results of a comparison of these sequences with homologous sequences from several proteobacterial species supported affiliation of $T$. cuprinus with the $\beta 1$ subgroup of the Proteobacteria. T. cuprinus, Thiobacillus intermedius, Thiobacillus perometabolis, and Thiobacillus thermosulfatus form a phylogenetic cluster that comprises some of the thiobacilli capable of mixotrophic growth. This cluster is related to some pseudomonads and Alcaligenes species belonging to the $\beta$ subclass. In addition, a low-frequency restriction fragment analysis (LFRFA) of some mixotrophic thiobacilli and some related species was carried out by using pulsed-field gel electrophoresis (PFGE) to determine the $\mathrm{SpeI}$ and $\mathrm{XbaI}$ macrorestriction patterns and genome sizes of these organisms. The correlation of the LFRFA results and the 16S rDNA analysis results and the usefulness of the two analyses are discussed. The PFGE fingerprints suggested that Thiobacillus sp. strain ATCC 27793 is related to $T$. intermedius rather than to $T$. perometabolis, as described previously. The distinctive characteristics of the mixotrophic species analyzed in this work, their phylogenetic relatedness, and their physiological differences from other groups belonging to the Proteobacteria, including other thiobacilli, suggest that these organisms should be transferred to a new genus, the genus Thiomonas gen. nov.
\end{abstract}

The genus Thiobacillus has been defined by its main feature, the ability to generate energy from oxidation of inorganic sulfur compounds. In addition, almost all species possess the enzyme ribulose bisphosphate carboxylase and, therefore, can fix atmospheric carbon dioxide. However, many species can grow under organotrophic conditions and exhibit variable patterns of utilization of organic compounds as carbon and/or energy sources. A large number of strains belonging to the genus Thiobacillus have been described previously. These strains exhibit a wide variety of types of metabolism. The first isolates, including isolates of the type species, Thiobacillus thioparus, were strict chemolithoautotrophs (Thiobacillus denitrificans, Thiobacillus thiooxidans, and Thiobacillus ferrooxidans), all of which have highly specialized metabolism. More recently, facultative organotrophs have been described; these organisms have more versatile types of physiology and can grow autotrophically, heterotrophically, and mixotrophically. The best-known species in this group are Thiobacillus cuprinus, Thiobacillus intermedius, Thiobacillus perometabolis, and Thiobacillus thermosulfatus $(13,19,34)$.

Extensive characterization of some thiobacilli has allowed workers to define physiological groups (12). Preliminary genetic data for the genus based on $\mathrm{G}+\mathrm{C}$ genomic composition and interspecific DNA-DNA hybridization values, which were obtained to extend the physiological classification to the genetic level, revealed a great range of genetic heterogeneity similar to the physiological heterogeneity. However, there is not a strict correspondence between the physiological and genetic groups. Later phylogenetic analyses confirmed the need for a taxonomic revision of the genus. Indeed, 5S rRNA phylogenetic analyses (22), as well as 16S rRNA phylogenetic analyses $(8,21)$, have revealed that Thiobacillus species are distributed in three of the subclasses of the Proteobacteria, the

* Corresponding author. Mailing address: Centro de Biología Molecular "Severo Ochoa," Lab. C-101, Universidad Autónoma de Madrid, Cantoblanco, 28049 Madrid, Spain. Phone: (34) 13978077. Fax: (34) 13978087. E-mail: osantacruz@mvax.cbm.uam.es. $\alpha, \beta$, and $\gamma$ subclasses. The results of these analyses prove that the ability to oxidize sulfur is found in many groups of gramnegative bacteria. Therefore, this metabolic capacity, together with rod-shaped morphology, cannot be considered a useful taxonomic criterion for inclusion of new species in the genus Thiobacillus. This is especially evident given that some photosynthetic bacteria (e.g., Chromatium and Chlorobium species) and some hydrogen-oxidizing Alcaligenes species can grow autotrophically by using sulfur compounds as sole energy sources $(2,6,16,19)$. Consequently, molecular genetic studies, such as rRNA sequence comparisons, instead of classic physiological analyses seem to be the best tools for taxonomic analyses of sulfur oxidizers. Thus, rRNA sequence analyses have allowed workers to transfer Thiobacillus versutus and Thiobacillus thyasiris to their correct positions in the genera Paracoccus (17) and Thiomicrospira (42), respectively.

Although, as mentioned above, there is poor correlation between the genetic and physiological groups, it is possible to establish clear relationships between some of the phylogenetic clusters and their metabolic characteristics. For instance, some of the strictly chemolithoautotrophic thiobacilli (Thiobacillus ferrooxidans, Thiobacillus thiooxidans, Thiobacillus sp. strain DSM 612 [probably a strain of Thiobacillus albertis], and Thiobacillus tepidarius) fall into a compact group in the $\beta$ subclass of the Proteobacteria (21). The following data also suggest that some of the facultatively organotrophic and mixotrophic species (Thiobacillus cuprinus, Thiobacillus intermedius, Thiobacillus perometabolis, and Thiobacillus thermosulfatus) are phylogenetically related: (i) $5 \mathrm{~S}$ rRNA (22) and partial $16 \mathrm{~S}$ rRNA $(39,41)$ sequence comparison data showed that Thiobacillus intermedius and Thiobacillus perometabolis are closely related; (ii) $16 \mathrm{~S}$ rRNA sequence analysis data recently revealed that Thiobacillus perometabolis is very similar to Thiobacillus thermosulfatus (34); and (iii) 23S rRNA sequence analysis data for another mixotroph, Thiobacillus cuprinus, supported its location in the $\beta 1$ subgroup and its relatedness to the Thiobacillus intermedius-Thiobacillus perometabolis branch (27).

We analyzed the complete $5 \mathrm{~S}$ and $16 \mathrm{~S}$ ribosomal DNA (rDNA) sequences of Thiobacillus cuprinus and compared 
these sequences with the sequences of other proteobacteria. Our data confirmed the existence of a phylogenetic cluster which groups Thiobacillus species capable of mixotrophic growth with other organisms belonging to diverse genera (such as the genera Pseudomonas, Burkholderia, Alcaligenes, and Bordetella) that have interesting metabolic relationships with sulfur compounds. In addition, a low-frequency restriction fragment analysis (LFRFA) (10) of the mixotrophic thiobacilli and related species, performed by using pulsed-field gel electrophoresis (PFGE), revealed that the genomic heterogeneity of this group was greater than the genetic heterogeneity exhibited by the rDNA sequences.

\section{MATERIALS AND METHODS}

Bacterial strains. Thiobacillus cuprinus DSM $5495^{\mathrm{T}}(\mathrm{T}=$ type strain) was used for $5 \mathrm{~S}$ and 16S rDNA sequence determinations. This strain, Thiobacillus intermedius ATCC $15466^{\mathrm{T}}$, Thiobacillus perometabolis ATCC $23370^{\mathrm{T}}$, Thiobacillus $\mathrm{sp}$. strain ATCC 27793, Burkholderia cepacia ATCC 17759, and Comamonas testos teroni ATCC 11996 were used for an LFRFA. The media recommended by the culture collections (Deutsche Sammlung von Mikroorganismen und Zellkulturen and American Type Culture Collection) were used to grow the strains

Determination of the sensitivity of Thiobacillus perometabolis to ampicillin. Thiobacillus perometabolis cultures were grown in specific liquid medium in the presence of ampicillin concentrations ranging from 0.01 to $10 \mu \mathrm{g} \mathrm{ml}^{-1}$. Sensitivity was estimated directly by measuring growth turbidimetrically.

Preparation, restriction, and PFGE of genomic DNA. Genomic DNAs of the strains listed above were prepared, put into low-melting-point agarose plugs, and digested with restriction endonucleases as described previously (35) by using the modifications of the cell-washing steps described by Kondrat'eva and Karavaiko (20) for chemolithotrophic strains of Thiobacillus cuprinus, Thiobacillus intermedius, and Thiobacillus perometabolis and Thiobacillus sp. strain ATCC 27793. Genomic DNAs were digested with restriction endonucleases SpeI and $\mathrm{Xba}$ (New England Biolabs, Beverly, Mass.) and were separated by orthogonal field alternating gel electrophoresis (35) and contour-clamped homogeneous electric field electrophoresis (3) performed with an LKB Pulsaphor system (Pharmacia Uppsala, Sweden) under the following conditions: $10 \mathrm{~h}$ and $13 \mathrm{~V} \mathrm{~cm}^{-1}$ for pulse times of 5,10 , and $15 \mathrm{~s} ; 36 \mathrm{~h}$ and $6 \mathrm{~V} \mathrm{~cm}^{-1}$ for a pulse time of $50 \mathrm{~s}$; and $170 \mathrm{~h}$ and $3 \mathrm{~V} \mathrm{~cm}^{-1}$ for a pulse time of $4,500 \mathrm{~s}$. The buffer used was $0.5 \times \mathrm{TBE}(1 \times$ TBE is $0.089 \mathrm{M}$ Tris, $0.089 \mathrm{M}$ boric acid, and $0.002 \mathrm{M}$ EDTA), and the constant running temperature was $10^{\circ} \mathrm{C}$. Chromosomes of Schizosaccharomyces pombe (prepared in our laboratory), phage lambda DNA concatemers, and phage lambda DNA digested with HindIII (New England Biolabs) were used as molecular size markers.

LFRFA. SpeI and $X b a \mathrm{I}$ macrorestriction patterns of some mixotrophic thiobacilli (Thiobacillus cuprinus, Thiobacillus intermedius, Thiobacillus perometabolis, and Thiobacillus sp. strain ATCC 27793), Thiobacillus ferrooxidans, Thiobacillus thiooxidans, Burkholderia cepacia, Comamonas testosteroni, and Bordetella pertussis were compared by using Dice coefficients, and preparing individual distance matrices for the SpeI and $X b a \mathrm{I}$ data and a combined matrix for all of the data. The Spel and $X b a I$ macrorestriction data for Thiobacillus ferrooxidans ATCC 21834, Thiobacillus thiooxidans ATCC 19377, and Bordetella pertussis Tohama I have been published previously $(14,38)$ and were included in the comparisons so that the analysis could be applied to other phylogenetically related organisms. Similarity dendrograms were created from each matrix by using the unweighted pair group with mathematical average clustering method (36) of the program TAXAN (Information Resources Group, Maryland Biotechnology Institute).

Thiobacillus cuprinus $5 S$ and $16 S$ rDNA cloning and sequencing. Thiobacillus cuprinus ribosomes were isolated by the method described by Stahelin and Maglott for Escherichia coli (37). 5S, 16S, and 23S rRNAs were purified as described by Amils et al. (1). Each rRNA was separately isolated from standard $1 \%$ agarose gels, eluted from agarose by phenol extraction, and $5^{\prime}$ end labeled by using bacteriophage T4 polynucleotide kinase and $\left[\gamma^{32}\right.$ P $]$ ATP. The rRNA probes obtained were used in hybridization experiments that were carried out at $55^{\circ} \mathrm{C}$ with blots containing SpeI- and Bam HI-SpeI-digested Thiobacillus cuprinus genomic DNA. The following two DNA bands that exhibited hybridization signals were selected: a 6-kbp SpeI band containing part of the $23 \mathrm{~S}$ rDNA and the $5 S$ rDNA and a $2.2-\mathrm{kbp} \mathrm{BamHI}$-SpeI band containing the rest of the 23S rDNA and the 16S rDNA. These two genomic fragments were cloned into appropriately restricted pBluescript $\mathrm{KS}^{-}$vector (Stratagene, La Jolla, Calif.), which resulted in clones pSU and pEx-SL, respectively. Following restriction mapping and subcloning of both clones, the nucleotide sequences of the $5 \mathrm{~S}$ and $16 \mathrm{~S}$ rDNAs were determined by standard dideoxy sequencing techniques by using Sequenase version 2.0 (United States Biochemical Corp., Cleveland, Ohio) and universal and reverse M13 primers, as well as synthetic oligonucleotides complementary to previously sequenced regions. Overlapping sequences were aligned by using the programs Bestfit and Assemble of the Genetics Computer Group software sys-
TABLE 1. Accession numbers of the $5 \mathrm{~S}$ and $16 \mathrm{~S}$ rRNA sequences used in this study

\begin{tabular}{|c|c|c|}
\hline \multirow{2}{*}{ Organism } & \multicolumn{2}{|r|}{ Sequence accession no. } \\
\hline & 5S rRNA & 16S rRNA \\
\hline Acidiphilium cryptum & M11545 & \\
\hline Agrobacterium tumefaciens & $\mathrm{X} 02627$ & \\
\hline Alcaligenes eutrophus & & M32021 \\
\hline Alcaligenes faecalis & X05517 & M22508 \\
\hline Alcaligenes xylosoxidans & X05524 & M22509 \\
\hline Bordetella avium & & U04947 \\
\hline Bordetella pertussis & & U04950 \\
\hline Burkholderia cepacia & X02629 & M22518 \\
\hline Burkholderia caryophyli & & $\times 67039$ \\
\hline Burkholderia gladioli & & $\mathrm{X} 67038$ \\
\hline Burkholderia solanacearum & & $\times 67040$ \\
\hline Comamonas testosteroni & & M11224 \\
\hline Escherichia coli & К00609 & \\
\hline Galionella ferruginea & & L07897 \\
\hline Leptothrix discophora & & L33974 \\
\hline Nitrosomonas europaea & & M96399 \\
\hline Paracoccus versutus & M11543 & \\
\hline Pseudomonas aeruginosa & X01556 & \\
\hline Pseudomonas fluorescens & X01557 & \\
\hline Rhodobacter capsulatus & X04585 & \\
\hline Rhodobacter sphaeroides & $\mathrm{X} 05520$ & \\
\hline Rubrivivax gelatinosus & & M60682 \\
\hline Sphaerotilus natans & & L33976, L33977, L33978 \\
\hline Thiobacillus acidophilus & M11546 & \\
\hline Thiobacillus cuprinus & U67161 & U67162 \\
\hline Thiobacillus intermedius & M11538 & \\
\hline Thiobacillus ferrooxidans & M11542 & X75267 \\
\hline Thiobacillus neapolitanus & M11537 & M79418, M79419, M79420 \\
\hline Thiobacillus novellus & M11544 & \\
\hline Thiobacillus perometabolis & M11539 & M79421, M79422, M79423 \\
\hline Thiobacillus tepidarius & & M79424, M79425 \\
\hline Thiobacillus thermosulfatus & & U27839 \\
\hline Thiobacillus thioparus & M11540 & M79426 \\
\hline Thiobacillus thiooxidans & M11541 & M79401 \\
\hline Thiomicrospira pelophila & M11535 & \\
\hline Thiothrix nivea & M35563 & \\
\hline Thiovulum sp. & M35570 & \\
\hline
\end{tabular}

tem (7). The secondary structure of the $16 \mathrm{~S}$ rRNA was predicted manually on the basis of the model of Gutell et al. (11).

Phylogenetic analysis. Thiobacillus cuprinus 5S and 16S rDNA sequences were aligned with homologous sequences of selected species (Table 1) obtained from the EMBL and GenBank data banks. The sequences were aligned by using the Pileup program (7) and primary and secondary structural characteristics (29). No secondary-structure differences between Thiobacillus cuprinus $5 \mathrm{~S}$ and $16 \mathrm{~S}$ rRNAs and other bacterial rRNAs were found. Distances were calculated from the aligned sequences by using the program Distances (7) and the assumptions of Jukes and Cantor (15) and omitting regions where there were terminal length variations and ambiguous sequence positions. $5 \mathrm{~S}$ and $16 \mathrm{~S}$ rDNAs trees were inferred from evolutionary distances by using a distance approach and the neighbor-joining clustering method (33) of the program Growtree (7). A bootstrap analysis performed with 100 subsamples from the data matrix was used to assess the degree of support of the sequence data for the resulting trees.

Nucleotide sequence accession numbers. The $5 \mathrm{~S}$ and $16 \mathrm{~S}$ rDNA sequences of Thiobacillus cuprinus have been deposited in the GenBank data library under accession numbers U67161 and U67162, respectively. The accession numbers of the nucleotide sequences of the $5 \mathrm{~S}$ and $16 \mathrm{~S}$ rRNAs of Thiobacillus cuprinus and other bacteria used for comparison are listed in Table 1 .

\section{RESULTS}

Thiobacillus cuprinus $5 \mathrm{~S}$ and $16 \mathrm{~S}$ rDNA sequence alignment. The $3^{\prime}$ and $5^{\prime}$ ends of Thiobacillus cuprinus $5 \mathrm{~S}$ and $16 \mathrm{~S}$ rRNAencoding genes were inferred by comparing their sequences with the sequences of homologous genes of phylogenetically related proteobacteria. The 5S rDNA sequence obtained was 


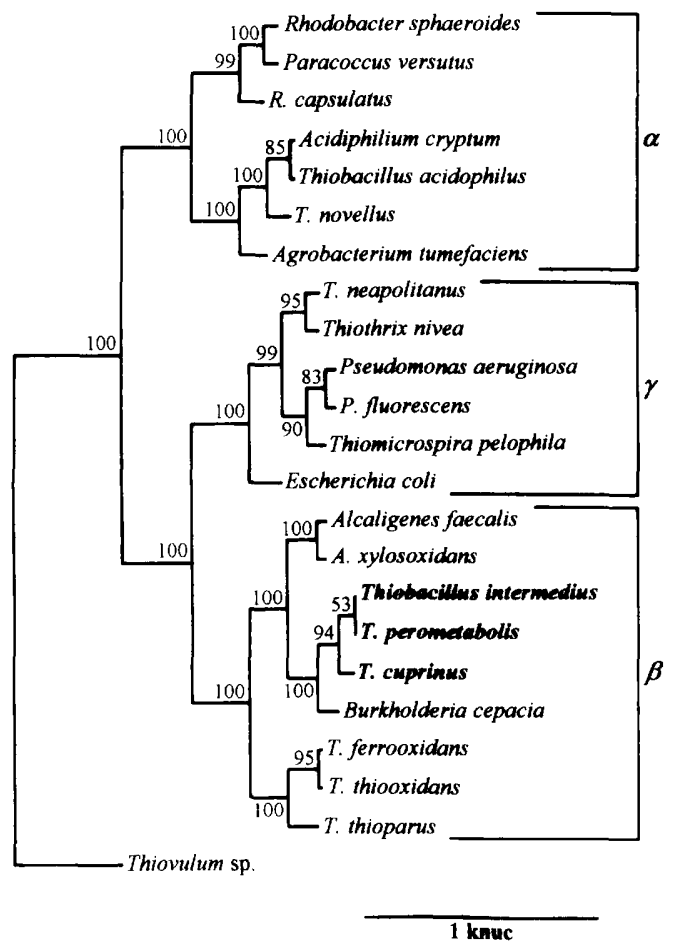

FIG. 1. Phylogenetic tree inferred from a comparison of 5S rRNA sequences of $\alpha, \beta$, and $\gamma$ subclass proteobacteria, showing the location of the mixotrophic thiobacilli within the $\beta$ subdivision. Thiovulum $\mathrm{sp}$. ( $\varepsilon$ subdivision) was used as the outgroup. Scale bar = evolutionary distance of $1 \mathrm{~K}_{\text {nuc }}$ (average number of nucleotide changes per sequence position). The numbers are bootstrap values.

117 nucleotides long, like the sequence of the related species Thiobacillus intermedius. An alignment of this sequence with some available homologous proteobacterial sequences revealed high degrees of similarity to the $5 \mathrm{~S}$ rDNAs of the species belonging to the $\beta 1$ subgroup (Alcaligenes faecalis, Alcaligenes sp., Burkholderia cepacia, Thiobacillus intermedius, and Thiobacillus perometabolis). These species had a 3-nucleotide deletion between positions 81 and 83 (Escherichia coli 5S rRNA numbering) that was absent in the sequences of organisms belonging to other $\beta$ subclass subgroups (e.g., Thiobacillus ferrooxidans, Thiobacillus thiooxidans and Thiobacillus thiopa$r u s)$. Such a deletion seems to be a distinctive peculiarity of the $\beta 1$ subgroup.

The Thiobacillus cuprinus 16S rRNA sequence did not exhibit any unusual features when it was compared with the sequences of other $\beta$ subclass proteobacteria. The predicted secondary structure of this sequence had the characteristic short stem (positions 184 to 193) and long stem (positions 198 to 219) described previously for $\beta$ and $\gamma$ subclass rRNAs (21) (data not shown). The highest similarity value $(90.1 \%)$ was obtained in the comparison with the Thiobacillus perometabolis sequence, which supported the hypothesis that Thiobacillus cuprinus is affiliated with the $\beta 1$ subgroup of the Proteobacteria. The gene sequenced had a G+C content of $55.09 \mathrm{~mol} \%$, a value which is much lower than the average values for complete genomes (65 to $67 \mathrm{~mol} \%$ ) reported by Huber and Stetter (13).

Phylogenetic analysis. The phylogenetic analyses of $5 \mathrm{~S}$ and $16 \mathrm{~S}$ rRNA sequences yielded similar results. Figure 1, a phylogenetic tree inferred from the $5 \mathrm{~S}$ rRNA sequences, shows the results of a general survey of the $\alpha, \beta$, and $\gamma$ subclasses of the Proteobacteria, rooted by the subclass $\varepsilon$ organism Thiovulum

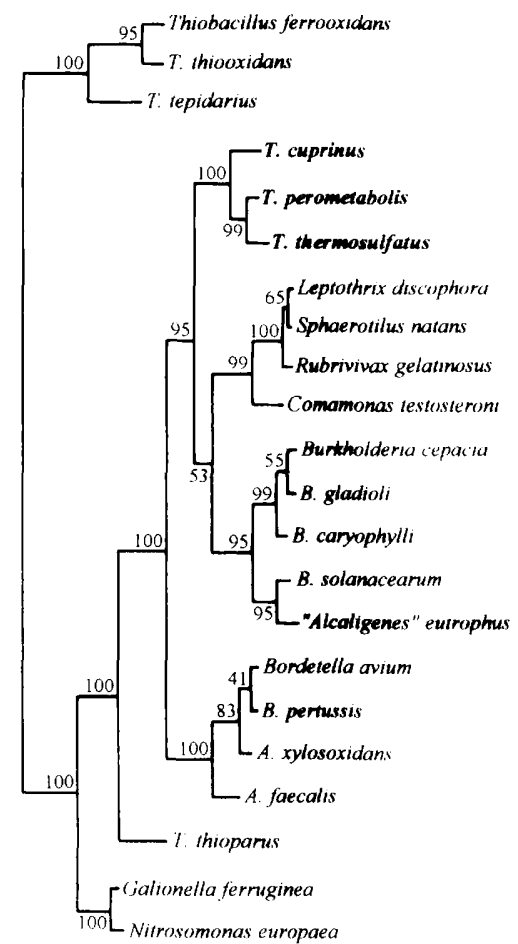

0.1 knuc

FIG. 2. Phylogenetic tree inferred from a comparison of 16S rRNA sequences of $\beta$ subdivision proteobacteria, showing the location of the mixotrophic thiobacilli and their phylogenetic relationships to other species. Scale bar = evolutionary distance of $0.1 \mathrm{~K}_{\text {nuc }}$. The numbers are bootstrap values.

sp., which support placement of Thiobacillus cuprinus in a cluster with two other facultative chemolithotrophs, Thiobacillus intermedius and Thiobacillus perometabolis, in the $\beta 1$ subgroup of the $\beta$ subclass. The results of the more detailed 16S rRNA analysis were especially interesting; this analysis revealed the relationship of the cluster to other species and genera of the $\beta$ subclass (Fig. 2).

Genome size determination and LFRFA. Nonrestricted intact genomic DNAs from Thiobacillus perometabolis, Thiobacillus sp. strain ATCC 27793, Thiobacillus intermedius, Thiobacillus cuprinus, Burkholderia cepacia, and C. testosteroni were subjected to PFGE, and the genomic sizes of these strains were found to range from $3.5 \mathrm{Mbp}$ (Thiobacillus cuprinus) to $6 \mathrm{Mbp}$ (Burkholderia cepacia) (data not shown). In order to obtain more accurate genome sizes, the genomic DNAs were treated with restriction endonucleases $S p e I$ and $X b a I$ and the resulting fragments were resolved by PFGE. The genome sizes were calculated by adding the sizes of the restriction fragments. These sizes, as suggested by the previous analysis of intact genomic DNAs, were within a wide range (from 3.6 Mbp for Thiobacillus cuprinus to $5.7 \mathrm{Mbp}$ for Burkholderia cepacia), indicating that the degree of genomic diversity was high. The resulting values were $3.6 \mathrm{Mbp}$ for Thiobacillus cuprinus, 4.5 Mbp for Thiobacillus sp. strain ATCC 27793, 4.8 Mbp for Thiobacillus perometabolis, $5.2 \mathrm{Mbp}$ for Thiobacillus intermedius, and $5.7 \mathrm{Mbp}$ for Burkholderia cepacia.

The restriction profiles (restriction fragment length polymorphisms as determined by PFGE [PFGE-RFLPs]) of the strains analyzed were heterogeneous (Fig. 3). The high numbers of restriction sites for endonucleases SpeI and $X b a \mathrm{I}$ in the genome of Thiobacillus perometabolis were remarkable; there 


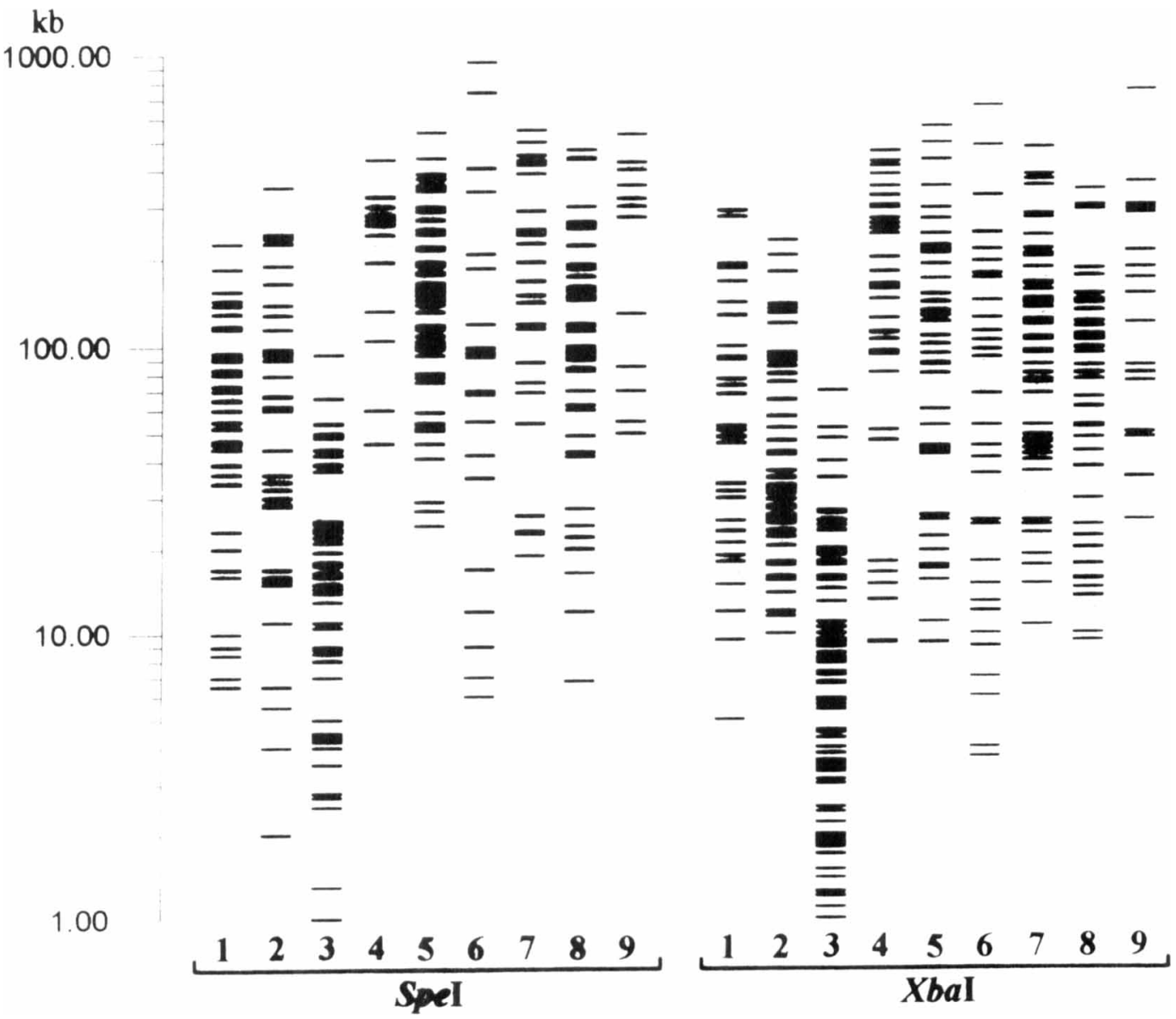

FIG. 3. Complete SpeI and XbaI macrorestriction patterns of Thiobacillus ferrooxidans (lane 1), Thiobacillus thiooxidans (lane 2), Thiobacillus perometabolis (lane 3), Thiobacillus sp. strain ATCC 27793 (lane 4), Thiobacillus intermedius (lane 5), Thiobacillus cuprinus (lane 6), Burkholderia cepacia (lane 7), C. testosteroni (lane 8) and Bordetella pertussis (lane 9). The patterns for Thiobacillus thiooxidans and Thiobacillus ferrooxidans were adapted from the patterns described by Irazabal et al. (14); the pattern for Bordetella pertussis was adapted from the pattern described by Stibitz and Garletts (38).

were more than 150 sites in both cases. The statistical analysis (unweighted pair group with mathematical average clustering) of the restriction profiles obtained in this work, complemented with previously reported restriction profiles for Thiobacillus ferrooxidans, Thiobacillus thiooxidans, and Bordetella pertussis $(14,38)$, yielded the similarity dendrogram presented in Fig. 4. This dendrogram shows interspecific relationships different from those inferred from the $5 \mathrm{~S}$ and $16 \mathrm{~S}$ rDNA sequence analyses. Also, it reflects the unusual restriction pattern of Thiobacillus perometabolis, since this species appears not to be very closely related to the rest of species belonging to the $\beta 1$ subgroup despite the results obtained in the sequence comparison.

\section{DISCUSSION}

The phylogenetic analysis of the 5S rDNA sequence of Thiobacillus cuprinus showed that this species is closely related to two other thiobacilli that exhibit optimum growth under mixotrophic conditions, Thiobacillus intermedius and Thiobacillus perometabolis (Fig. 1), while the comparison of $16 \mathrm{~S}$ rDNA sequences led to inclusion of Thiobacillus thermosulfatus in this cluster (Fig. 2). This evolutionary relationship is consistent with some structural and physiological characteristics shared by these species (Table 2), such as ubiquinone content, pres- ence of $\alpha$-oxoglutarate dehydrogenase and metabolic abilities $(13,19,22,34)$. These species form a compact cluster within the $\beta 1$ subgroup of the Proteobacteria, suggesting that their characteristic metabolism had a common evolutionary origin. Our study of the relationships of this cluster to other bacteria in the $\beta$ subclass, performed by comparing $16 \mathrm{~S}$ rDNA sequences, allowed us to formulate some evolutionary hypothe-

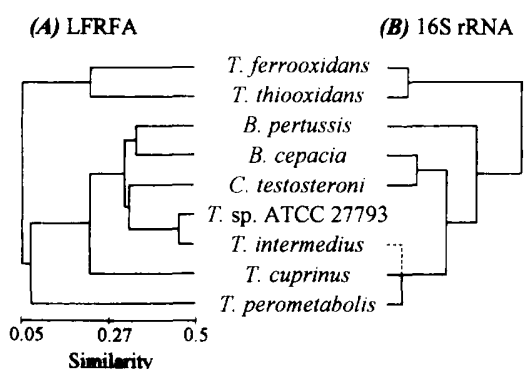

FIG. 4. (A) Similarity dendrogram obtained from a comparison of the macrorestriction patterns of the strains analyzed. The bar indicates a similarity values. (B) Schematic dendrogram showing the relationships of the species inferred from the 16S rRNA sequence comparison (Fig. 2), with Thiobacillu. intermedius (discontinuous line) included at the position suggested by Takakuwa (39). The branch lengths are not drawn to scale. 
TABLE 2. Characteristics of the mixotrophic thiobacilli studied and other Thiobacillus species

\begin{tabular}{|c|c|c|c|c|c|c|c|}
\hline \multirow[b]{2}{*}{ Characteristic } & \multicolumn{4}{|c|}{$\beta 1$ Subgroup mixotrophs. } & \multicolumn{3}{|c|}{ Other species } \\
\hline & $\begin{array}{l}\text { Thiobacillus } \\
\text { cuprinus }\end{array}$ & $\begin{array}{l}\text { Thiobacillus } \\
\text { intermedius }\end{array}$ & $\begin{array}{l}\text { Thiobacillus } \\
\text { perometabolis }\end{array}$ & $\begin{array}{c}\text { Thiobacillus } \\
\text { thermosulfatus }\end{array}$ & $\begin{array}{l}\text { Thiobacillus } \\
\text { acidophilus }\end{array}$ & $\begin{array}{l}\text { Thiobacillus } \\
\text { ferrooxidans }\end{array}$ & $\begin{array}{l}\text { Thiobacillus } \\
\text { neapolitanus }\end{array}$ \\
\hline Optimum $\mathrm{pH}$ & $2-4$ & $5-7$ & $5-7$ & $5-6$ & $2-4$ & $2-4$ & $6-8$ \\
\hline Optimum temp $\left({ }^{\circ} \mathrm{C}\right)$ & $30-37$ & $30-37$ & $30-37$ & 50 & $25-30$ & $25-30$ & $25-30$ \\
\hline Motility & $+^{\dot{a}}$ & + & + & + & + & + & + \\
\hline$\alpha$-Oxoglutarate dehydrogenase & $(-)$ & $(-)$ & $(-)$ & $(-)$ & $\mathrm{ND}$ & - & - \\
\hline \multicolumn{8}{|l|}{ Presence of: } \\
\hline Ubiquinone Q-8 & + & + & + & + & - & + & + \\
\hline Ubiquinone $\mathrm{Q}-10$ & - & - & - & - & + & - & - \\
\hline Obligate chemolithoautotroph & - & - & - & - & $\dot{-}$ & + & + \\
\hline Mixotrophic optimum growth & + & + & + & + & - & - & - \\
\hline \multicolumn{8}{|l|}{ Autotrophic growth with: } \\
\hline Sulfur & + & + & + & + & + & + & + \\
\hline Sulfide minerals & - & - & - & ND & - & + & - \\
\hline Pyrite & + & - & - & ND & - & + & - \\
\hline Ferrous iron & - & - & - & - & - & + & - \\
\hline Thiosulfate & - & + & + & + & + & + & + \\
\hline Tetrathionate & - & + & + & + & + & + & + \\
\hline Trithionate & - & ND & ND & ND & + & + & + \\
\hline Thiocyanate & - & - & - & - & - & - & - \\
\hline Formate & - & ND & ND & - & ND & + & - \\
\hline $\begin{array}{l}\text { Nutritional requirement for a reduced } \\
\text { inorganic sulfur compound }\end{array}$ & - & + & + & - & + & + & - \\
\hline Denitrification & - & - & - & - & - & - & - \\
\hline $\begin{array}{l}\text { Incorporation of organic substracts in } \\
\text { the presence of an oxidable sulfur } \\
\text { compound }\end{array}$ & + & + & + & + & + & - & + \\
\hline
\end{tabular}

${ }^{a}+$, positive; - , negative; $(-)$, extremely low concentration; ND, not determined.

ses. The analysis showed that the mixotrophic cluster is most closely related phylogenetically to the genera Leptothrix and Sphaerotilus (Fig. 2), the heterotrophic sheathed bacteria that accumulate $\mathrm{Fe}(\mathrm{OH})_{3}$ and oxidize $\mathrm{Mn}^{2+}(28)$, and to C. testosteroni. Within the $\beta 1$ subgroup, a large number of species belonging to other genera are closely related to these organisms; these species include members of rRNA homology group II of the pseudomonads (30) (type species, Burkholderia cepacia) and some representatives of the family Alcaligenaceae that belong to the genera Alcaligenes and Bordetella. All of the nonpathogenic species in this group except members of the genus Burkholderia and C. testosteroni exhibit chemolithotrophic hydrogenotrophic metabolism related to sulfur compounds. The remaining species are occasional parasites (Burkholderia spp., C. testosteroni, and even some Alcaligenes species) or obligate parasites (Bordetella spp.). However, some of these organisms grow in habitats with abundant organic sulfur compounds (Burkholderia cepacia) or have nutritional requirements for organic sulfur compounds (Bordetella spp.) (31), suggesting a possible evolutionary past related to sulfur metabolism. Furthermore, some phototrophic proteobacteria belonging to the $\beta$ subclass can get energy for growth from the oxidation of ferrous sulfide (5). In addition, the root of the $\beta$ subclass seems to be located near the phylogenetic branch that contains the strictly chemolithoautotrophic thiobacilli, Thiobacillus ferrooxidans, Thiobacillus thiooxidans, and Thiobacillus tepidarius (22). It is important to note that Thiobacillus ferrooxidans is also a hydrogen oxidizer (4), a characteristic that it has in common with other genera in this group of proteobacteria. The phylogenetic location of this organism, as well as the wide distribution of sulfur-, iron- and/or hydrogen-oxidizing chemolithotrophic species in the $\beta$ subdivision, could suggest that it had a chemolithotrophic phylogenetic origin, followed by a complex process of divergence that explains the actual meta- bolic profiles of members of this subclass. The existence of mixotrophic bacteria favors this hypothesis, since these organisms demonstrate that an evolutionary transition from lithotrophic metabolism to organotrophic metabolism is possible.

The topologies of the dendrogram obtained from the LFRFA and the small-subunit rDNA analysis in general are similar. Thus, there is a cluster that is formed by the $\beta 1$ subgroup species and includes Thiobacillus ferrooxidans and Thiobacillus thiooxidans. However, the results of the analysis of the PFGE-RFLPs differ significantly from the results of the phylogenetic study of 5S and 16S rDNA sequences for two of the species analyzed, Thiobacillus cuprinus and, especially, Thiobacillus perometabolis. To ascertain which pattern of specific relationships corresponds to the real phylogeny, other kinds of data could be considered. Thus, the distribution of species derived from the LFRFA study is not completely consistent with the physiological features; it breaks off the group containing the mixotrophic thiobacilli, which is consistently formed by rDNA phylogenetic analyses as well as by physiology. Thiobacillus perometabolis is identified by the LFRFA as the root of this group and is very distantly related to the rest of species despite its high levels of sequence and metabolic similarity to Thiobacillus cuprinus, Thiobacillus intermedius, and Thiobacillus thermosulfatus; this finding is also in contrast to the high levels of total DNA homology between Thiobacillus perometabolis and Thiobacillus intermedius, up to $78 \%$, which indicates that the relationship is very close (12). Although restriction endonucleases SpeI and $X b a \mathrm{I}$ have very low numbers of recognition sites in gram-negative bacteria (25), Thiobacillus perometabolis exhibits an unusually high restriction rate, which explains its location in the LFRFA study. In conclusion, the rDNA sequence analysis yielded a phylogenetic tree whose topology is consistent with the available physiological data, which more accurately represent the phylogeny of this group. 
A comparison of the two analyses and an estimate of the confidence levels obtained by using other data indicated that, in accordance with the observations of other workers, sequence analysis is more suitable than LFRFA for phylogenetic studies of organisms that do not belong to very closely related phylogenetic groups. In our study, the divergence times for all of the $\beta 1$ subgroup species included in the LFRFA, estimated by assuming that the average rate of sequence divergence for small-subunit rRNAs is $1 \%$ per $50 \times 10^{6}$ years $(40)$, are approximately $500 \times 10^{6}$ years, which has been proposed as the resolution limit for LFRFA (32). However, on the basis of our work, the resolution limit should be a divergence time of less than $300 \times 10^{6}$ years; with this value the two analyses (LFRFA and rRNA sequence analysis) are in agreement.

Despite the limitations for phylogenetic inference discussed above, LFRFA can be very useful as a taxonomic tool. Comparisons of PFGE-RFLPs help determine the correct affiliations of new strains in well-described species and have some advantages over classical morphological and physiological characterizations. Thus, the results of our LFRFA suggest that Thiobacillus sp. strain ATCC 27793 has been incorrectly classified as a Thiobacillus perometabolis strain (18), as it is much more closely related to Thiobacillus intermedius.

The results of the sequence analyses described in this paper support the hypothesis that the mixotrophic organisms Thiobacillus cuprinus, Thiobacillus intermedius, Thiobacillus perometabolis, and Thiobacillus thermosulfatus form a phylogenetic cluster within the $\beta 1$ subgroup of the Proteobacteria. These species share some physiological features that clearly differentiate them from other thiobacilli. An interesting development of our work will be phylogenetic characterization of other less-well-known mixotrophic thiobacilli, such as Thiobacillus sp. strain ATCC 27793, Thiobacillus sp. strain Q (9), and Thiobacillus delicatus (26), in order to get a sense of the putative affiliations of these organisms to the mixotrophic cluster.

Our data suggest that a taxonomic revision of the genus Thiobacillus is needed and that this could lead to reclassification of some of the mixotrophic thiobacilli in a new genus. In addition, the special metabolic abilities of the mixotrophic thiobacilli make them an excellent model for genetic studies of the regulation of carbon and sulfur utilization mechanisms. Therefore, a phylogenetic analysis of these bacteria should provide a framework for specific relationships that will be useful in applying the results of this study to other species and in clarifying the confused taxonomy of the genus Thiobacillus.

We propose that the genus Thiomonas gen. nov. should be created to accommodate the mixotrophic organisms Thiobacillus cuprinus, Thiobacillus intermedius, Thiobacillus perometabolis, and Thiobacillus thermosulfatus. We suggest that Thiomonas intermedius (type strain, ATCC 15466) should be the type species of the genus Thiomonas since it was the subject of many of the early studies that revealed the metabolic characteristics of the mixotrophs and it has been used very frequently for laboratory studies.

Description of Thiomonas gen. nov. Thiomonas (Thi.o. mo'nas. Gr. n. thios, sulfur; Gr. fem. n. monas, a unit, monad; M.L. fem. n. Thiomonas, sulfur monad). The phenotypic description of the genus Thiomonas is the same as the description of general traits published previously in Bergey's Manual of Systematic Bacteriology (19) for the species belonging to group II of the genus Thiobacillus. The cells of Thiomonas species are gram-negative, non-spore-forming, short rods that are about 0.3 to $0.5 \mu \mathrm{m}$ wide and 1 to $3 \mu \mathrm{m}$ long. Each cell is motile by means of one polar flagellum. Obligate aerobes. The optimum temperature is between 30 and $36^{\circ} \mathrm{C}$ for the mesophilic species and $50^{\circ} \mathrm{C}$ for the moderately thermophilic species. The opti- mum $\mathrm{pH}$ is between 3 and 6 . Not able to denitrify. Facultative chemolithoautotrophs. Optimum growth occurs in mixotrophic media supplemented with reduced sulfur compounds and organic supplements, such as yeast extract, peptone, some sugars, and some amino acids. Organotrophic growth occurs on yeast extract, peptone, Casamino Acids, and meat extract. Lithoautotrophic growth occurs on thiosulfate, tetrathionate, $\mathrm{H}_{2} \mathrm{~S}$, and elemental sulfur. No oxidation of ferrous iron occurs. Sulfuric acid is formed during lithotrophic growth. Sensitive to ampicillin. Contains ubiquinone 8 . The $\mathrm{G}+\mathrm{C}$ content of the DNA is between 61 and $69 \mathrm{~mol} \%$. These characteristics of the members of the genus Thiomonas are summarized and compared with the characteristics of some representative species of the genus Thiobacillus in Table 2.

The type species is Thiomonas intermedia; the type strain of this species is strain ATCC 15466. In addition to this type species, the genus comprises Thiomonas cuprina (13), Thiomonas perometabolis (24), and Thiomonas thermosulfata (34).

Description of Thiomonas cuprina (Huber and Stetter) comb. nov. The description of Thiomonas cuprina comb. nov. is identical to the description given by Huber and Stetter (13). The type strain is strain DSM 5495

Description of Thiomonas intermedia (London) comb. nov. The description of Thiomonas intermedia comb. nov. is identical to the description given by London (23). The type strain is strain ATCC 15466.

Description of Thiomonas perometabolis (London and Rittenberg) comb. nov. The description of Thiomonas perometabolis comb. nov. is identical to the description given by London and Rittenberg (24), with the following exception: growth is completely inhibited by $1 \mu \mathrm{g}$ of ampicillin per ml. The type strain is strain ATCC 23370.

Description of Thiomonas thermosulfata (Shooner et al.) comb. nov. The description of Thiomonas thermosulfata comb. nov. is identical to the description given by Shooner et al. (34). The type strain is strain ATCC 51520.

\section{ACKNOWLEDGMENTS}

This work was supported by grant BIO94-0733-C03-01 from the Comision Interministerial de Ciencia y Tecnologia, by grant BIOCT93-0274 from the European Community, and by an institutional grant to the Centro de Biología Molecular from the Fundación Ramón Areces.

\section{REFERENCES}

1. Amils, R., E. A. Matthews, and C. R. Cantor. 1979. Reconstitution of 50 S ribosomal subunits from Escherichia coli. Methods Enzymol. 59:449-461.

2. Brune, D. C. 1989. Sulfur oxidation by phototrophic bacteria. Biochim Biophys. Acta 975:189-221.

3. Chu, G., D. Vollrath, and R. W. Davies. 1984. Separation of large DNA molecules by contour-clamped homogeneous electric fields. Science 234; 1582-1585.

4. Drobner, E., H. Huber, and K. O. Stetter. 1990. Thiobacillus ferrooxidans, a facultative hydrogen oxidizer. Appl. Environ. Microbiol. 56:2922-2923.

5. Ehrenreich, A., and F. Widdel. 1994. Anaerobic oxidation of ferrous iron by purple bacteria, a new type of phototrophic metabolism. Appl. Environ. Microbiol. 60:4517-4526.

6. Friedrich, C. G., and G. Mitrenga. 1981. Oxidation of thiosulfate by Paracoccus denitrificans and other hydrogen bacteria. FEMS Microbiol. Lett. 10:209-212.

7. Genetics Computer Group. 1991. Program manual for the GCG package, version 7. Genetics Computer Group, Madison, Wis.

8. Goebel, B. M., and E. Stackebrandt. 1994. Cultural and phylogenetic analysi of mixed microbial populations found in natural and commercial bioleaching environments. Appl. Environ. Microbiol. 60:1614-1621.

9. Gommers, P. J. F., and J. G. Kuenen. 1988. Thiobacillus strain Q, a chemolithoheterotrophic sulphur bacterium. Arch. Microbiol. 150:117-125.

10. Grothues, D., and B. Tümmler. 1991. New approaches in genome analysis by pulsed field gel electrophoresis: application to the analysis of Pseudomonas species. Mol. Microbiol. 5:2763-2776.

11. Gutell, R. R., N. Larsen, and C. R. Woese. 1994. Lessons from an evolving 
rRNA: $16 \mathrm{~S}$ and $23 \mathrm{~S}$ rRNA structures from a comparative perspective. Microbiol. Rev. 58:10-26.

12. Harrison, A. P., Jr. 1983. Genomic and physiological comparisons between heterotrophic thiobacilli and Acidiphilium cryptum, Thiobacillus versutus $\mathrm{sp}$ nov., and Thiobacillus acidophilus nom. rev. Int. J. Syst. Bacteriol. 33:211217.

13. Huber, H., and K. O. Stetter. 1990. Thiobacillus cuprinus sp. nov., a nove facultatively organotrophic metal-mobilizing bacterium. Appl. Environ. Microbiol. 56:315-322.

14. Irazabal, N., D. Moreira, R. Amils, and I. Marín. 1995. Comparative genomic organization of thiobacilli using pulsed field gel electrophoresis, $\mathrm{p}$. 31-41. In C. A. Jerez, T. Vargas, H. Toledo, and J. V. Wiertz (ed.), Biohydrometallurgical processing. University of Chile, Santiago, Chile.

15. Jukes, T. H., and C. R. Cantor. 1969. Evolution of protein molecules, p 21-132. In H. N. Munro (ed.), Mammalian protein metabolism. Academic Press, New York, N.Y.

16. Kämpf, C., and N. Pfennig. 1980. Capacity of Chromatiaceae for chemotrophic growth. Specific respiration rates of Thiocystis violacea and Chromatium vinosum. Arch. Microbiol. 127:125-135.

17. Katayama, Y., A. Hiraishi, and H. Kuraishi. 1995. Paracoccus thiocyanatus sp. nov., a new species of thiocyanate-utilizing facultative chemolithotroph, and transfer of Thiobacillus versutus to the genus Paracoccus as Paracoccus versutus comb. nov. with emendation of the genus. Microbiology 141:14691477 .

18. Katayama-Fujimura, Y., N. Tsuzaki, and H. Kuraishi. 1982. Ubiquinone, fatty acid and DNA base composition determination as a guide to the taxonomy of the genus Thiobacillus. J. Gen. Microbiol. 128:1599-1611.

19. Kelly, P. D., and A. P. Harrison. 1989. Genus Thiobacillus, p. 1842-1858. In J. T. Staley, M. P. Bryant, N. Pfennig, and J. G. Holt (ed.), Bergey's manual of systematic bacteriology, vol. 3. Williams \& Wilkins, Baltimore, Md.

20. Kondrat'eva, T. F., and G. I. Karavaiko. 1992. Restriction analysis of Thiobacillus ferrooxidans DNA by electrophoresis in pulsating differently-directed electric fields. Mol. Genet. Mikrobiol. Virusol, 3-4:9-12.

21. Lane, D. J., A. P. Harrison, Jr., D. Stahl, B. Pace, S. J. Giovannoni, G. J. Olsen, and N. R. Pace. 1992. Evolutionary relationships among sulfur- and iron-oxidizing eubacteria. J. Bacteriol. 174:269-278.

22. Lane, D. J., D. A. Stahl, G. J. Olsen, D. J. Heller, and N. R. Pace. 1985 Phylogenetic analysis of the genera Thiobacillus and Thiomicrospira by $5 \mathrm{~S}$ rRNA sequences. J. Bacteriol. 163:75-81.

23. London, J. 1963. Thiobacillus intermedius nov. sp. A novel type of facultative autotroph. Arch. Mikrobiol. 46:329-337.

24. London, J., and S. C. Rittenberg. 1967. Thiobacillus perometabolis nov. sp., a nonautotrophic Thiobacillus. Arch. Mikrobiol. 59:218-225.

25. McClelland, M., R. Jones, J. Patel, and M. Nelson. 1987. Restriction endonucleases for pulsed field mapping of bacterial genomes. Nucleic Acids Res. 15:5985-6005.

26. Mizoguchi, T., T. Sato, and T. Okabe. 1976. New sulphur-oxidizing bacteria capable of growing heterotrophically, Thiobacillus rubellus nov. sp. and Thiobacillus delicatus nov. sp. J. Ferment. Technol. 54:181-191.

27. Moreira, D., R. Amils, and I. Marín. 1994. Complete primary structure of the 23S rRNA coding gene from Thiobacillus cuprinus and its similarity with that of Burkholderia cepacia. Syst. Appl. Microbiol. 17:481-483.

28. Mulder, E. G. and M. H. Deinema. 1981. The sheathed bacteria p. 425-440. In M. P. Starr, H. Stolp, H. G. Trüper, A. Balows, and H. G. Schlegel (ed.) The prokaryotes: a handbook on habitats, isolation and identification of bacteria. Springer-Verlag, Heidelberg, Germany.

29. Olsen, G. J. 1988. Phylogenetic analysis using ribosomal RNA. Methods. Enzymol. 164:793-812.

30. Palleroni, N. 1984. Genus I. Pseudomonas Migula $1894,237^{\text {AL }}$, p. 141-199. In N. R. Krieg and J. G. Holt (ed.), Bergey's manual of systematic bacteriology, vol. 1. Williams \& Wilkins, Baltimore, Md.

31. Pittman, M. 1984 Genus Bordetella Moreno-López 1952, $178^{\mathrm{AL}}$, p. 388-393. In N. R. Krieg and J. G. Holt (ed.), Bergey'manual of systematic bacteriology, vol. 1. Williams \& Wilkins, Baltimore, Md.

32. Rodrigo, A. G., K. M. Borges, and P. L. Bergquist. 1994. Pulsed-field ge electrophoresis of genomic digests of Thermus strains and its implications for taxonomic and evolutionary studies. Int. J. Syst. Bacteriol. 44:547-552.

33. Satiou, N., and M. Nei. 1987. The neighbor-joining method: a new method for reconstructing phylogenetic trees. Mol. Biol. Evol. 4:406-425.

34. Schooner, F., J. Bousquet, and R. Tyagi. 1996. Isolation, phenotypic characterization, and phylogenetic position of a novel, facultatively autotrophic moderately thermophilic bacterium, Thiobacillus thermosulfatus $\mathrm{sp}$. nov. Int. J. Syst. Bacteriol. 46:409-415.

35. Smith, C. L., S. R. Klco, and C. R. Cantor. 1988. Pulsed-field gel electrophoresis and the technology of large DNA molecules, p. 41-72. In K. Davies (ed.), Genome analysis: a practical approach. IRL Press, Oxford, England.

36. Sneath, P. H. A., and R. R. Sokal. 1973. Numerical taxonomy. W. H. Freeman and Company, San Francisco, Calif.

37. Stahelin, T., and D. Maglott. 1971. Preparation of Escherichia coli ribosoma subunits active in polypeptide synthesis. Methods Enzymol. 20:449-456.

38. Stibitz, S., and T. L. Garletts. 1992. Derivation of a physical map of the chromosome of Bordetella pertussis Tohama I. J. Bacteriol. 174:7770-7777.

39. Takakuwa, S. 1992. Biochemical aspects of microbial oxidation of inorganic sulfur compounds, p. 1-43. In S. Oae and T. Okuyama (ed.), Organic sulfur chemistry: biochemical aspects. CRC Press, Boca Raton, Fla.

40. Wilson, A. C., H. Ochman, and E. M. Prager. 1987. Molecular time scale for evolution. Trends Genet. 3:241-247.

41. Woese, C. R., W. G. Weisburg, B. J. Paster, C. M. Hahn, R. S. Tanner, N. R Krieg, H. P. Koops, H. Harms, and E. Stackebrandt. 1984. The phylogeny of purple bacteria: the beta subdivision. Syst. Appl. Microbiol. 5:327-336.

42. Wood, A. P., and D. P. Kelly. 1993. Reclassification of Thiobacillus thyasiris as Thiomicrospira thyasirae comb. nov., an organism exhibiting pleomorphism in response to environmental conditions. Arch. Microbiol. 159:45-47. 